\title{
Credibilidade de informações em tempos de COVID-19*
}

\author{
Juliana Fachin \\ Doutoranda e mestre pelo Programa de Pós- \\ Graduação em Ciência da Informação da \\ UFSC. Bacharel em Biblioteconomia pela \\ Universidade Federal de Santa Catarina. \\ Editora gerente na Revista Ágora. \\ Bolsista Capes. \\ julianafachin@gmail.com \\ https://orcid.org/0000-0003-0883-642X
}

\section{Nelma Camelo de Araujo}

Doutora e mestre pelo Programa de PósGraduação em Ciência da Informação da Universidade Federal de Santa Catarina, Professora adjunta e coordenadora no Curso de Biblioteconomia da Universidade Federal de Alagoas. araujo@ichca.ufal.br https://orcid.org/0000-0002-4892-7484

\footnotetext{
Juliana Carvalho de Sousa

Doutoranda em Administração pela Universidade Potiguar (UNP). Mestre em Administração pela Universidade Estadual do Ceará(UECE). Especialistaem Gestão Estratégica de Pessoase Liderança Organizacional, pela Faculdade Vale do Jaguaribe (FVJ).Docente substituta da Universidade do Estado do Rio Grande do Rio Grande do Norte(UERN) emembro do Banco de Avaliadores do Sistema Nacional de Avaliação daEducaçãoSuperior (BASis-INEP). juli.cs1009@gmail.com https://orcid.org/0000-0002-0388-3959
}

\section{Resumo}

Este estudo de reflexão é de cunho exploratório, descritivo. Como objetivo, buscou-se verificar elementos que possibilitem aferir credibilidade às informações disponíveis na Web. Para atender ao objetivo proposto, aplicou-se a revisão de literatura a fim de identificar publicações que tratam sobre os temas: fake news, pós-verdade, infodemia, desinformação, checagem e credibilidade de informações. Conclui-se que, o método de fact-checking foi considerado válido na creditação de conteúdo, uma vez que parte da checagem de todo o contexto informacional, passando por etapas de validação, no qual permite a transparência do método e das fontes checadas. Devido ao grande número de informações disponíveis na internet a prática de checagem de conteúdo se tornou necessária para a verificação e certificação de publicações, pertinentes ao interesse público, combatendo as fakes news e ao movimento da infodemia e desinformação da sociedade

Palavras-chave: fake news, pós-verdade, infodemia, desinformação, checagem de informação, credibilidade de informações.

Cómo citar este artículo: Fachin, Juliana; Araujo, Nelma Camelo de; Sousa, Juliana Carvalho de (2020). Credibilidade de informações em tempos de COVID-19. Revista Interamericana de Bibliotecologia, 43(3), eRf3. https://doi.org/10.17533/udea.rib.v43n3eRf3

Recibido: 2020-07-02 / Aceptado: 2020-08-18 


\section{Credibility of Information in Covid-19 Times}

\begin{abstract}
This reflection study is exploratory and descriptive. As a objective, we sought to verify elements that make it possible to assess the credibility of the information available on the Web. To meet the proposed objective, a literature review was applied in order to identify publications that deal with the topics: fake news, Post-truth, Infodemia, Misinformation, Checking and Credibility of information. It is concluded that the fact-checking method was considered valid in the content accreditation, since it starts from checking the entire informational context, going through validation steps, which allows the transparency of the method and the sources checked. Due to a large amount of information available on the internet, the practice of content checking has become necessary for the verification and certification of publications, relevant to the public interest, combating fake news and the movement of infodemia, and disinformation in today's society.
\end{abstract}

Keywords: Fake news, post-truth, infodemia, disinformation, information check, credibility of information.

\section{Credibilidad de la información en tiempos de la COVID-19}

\begin{abstract}
Este es un estudio de reflexión de tipo exploratorio y descriptivo. Como objetivo, se buscó verificar elementos que permiten evaluar la credibilidad de la información disponible en la web. Para cumplirlo, se aplicó una revisión de literatura con el fin de identificar las publicaciones que tratan de los siguientes temas: noticias falsas, posverdad, infodemia, desinformación, verificación y credibilidad de la información. Se concluyó que el método fact-checking se considera válido para comprobar el contenido, ya que permite la verificación de todo el contexto informativo, pasando por etapas de validación, en las que permite la transparencia del método y las fuentes comprobadas. Debido a la gran cantidad de información disponible en internet, la práctica de verificación del contenido se ha hecho indispensable para la verificación y certificación de publicaciones relevantes para el interés público, y así combatir las noticias falsas y el movimiento de la infodemia y la desinformación en la sociedad actual.
\end{abstract}

Palabras clave: noticias falsas, posverdad, infodemia, desinformación, verificación de la información, credibilidad de la información.

\section{Introdução}

A globalização da internet atrelada ao surgimento das redes sociais mudou a maneira de como as notícias são produzidas e publicadas, contribuindo para a rápida disseminação de fake news, que em tradução literal significa notícia falsa. Muitos desses conteúdos decorrem de fontes desconhecidas, criados facilmente por usuários das mídias sociais, que por meio da internet espalham informações, por vezes, enganosas, prejudicando pessoas, organizações e sociedade (Silva, Santos, Almeida \& Pardo 2020)

Nesse interim, fake news é associado ao termo "pós-verdade", ao explicar que quando notícias falsas são difundidas, principalmente através da internet, os indivíduos se importam mais com crenças pessoais sobre aquilo que se almejava consolidar do que com os fatos baseados em evidências, os quais passam a ter menor poder de convencimento e de formação de opinião (Sinatra \& Lombardi, 2020).

Em vistas disso, a disseminação descomedida de notícias falsas, nutridas pelas mídias sociais, apresentam um grande desafio para a sociedade, em especial nas áreas da saúde, devido o atual momento vivenciado advindo do novo coronavírus. A disseminação de informação falsas se propaga rápido e atrapalha às medidas de mitigação da COVID-19, recomendadas pela Organização Mundial da Saúde (OMS), principalmente no que tange sobre as ações associadas ao isolamento social, quarentena e cuidados para evitar o contágio, considerando-se que os indivíduos estão recorrendo veementemente aos meios digitais para a obtenção de informações e compartilhamento de notícias sobre o novo vírus (Limaye et al., 2020).

No entanto, desde os primeiros casos da doença em Wubei, na China, a desinformação se espalhou pelo mundo, dificultando a identificação de fontes confiáveis de informação (Mesquita, Oliveira, Seixas \& Paes, 2020). Uma pesquisa realizada pela Avaaz (2020), comunidade online de mobilização social global, sobre fake news e o novo coronavírus, apontou que $73 \%$ dos brasileiros acreditam em notícias falsas sobre a doença e que $94 \%$ tiveram acesso a pelo menos uma informação falsa sobre a Covid-19. 
Ademais, uma pesquisa realizada pela Organização das Nações Unidas (Unesco, 2020) em parceria com o International Center for Journalists (ICFJ), sobre notícias falsas durante a pandemia da Covid-19, apontou que as principais informações giram em torno da origem da doença, dos sintomas, diagnósticos e tratamento do vírus, podendo colocar vidas em risco ao levarem algumas pessoas a testarem remédios, não comprovados, na esperança de cura. Além disso, a pesquisa também apontou a disseminação de dados distorcidos relacionados ao número de pessoas infectadas e óbitos associados ao coronavirus.

Essas notícias comprometem a resposta ao surto da Covid-19, induzindo ao relaxamento das medidas de proteção; aumentando a confusão pública sobre quais fontes de informação confiar; gerando medo e pânico devido a rumores exagerados sem comprovações científicas, além de promoverem a xenofobia e o preconceito. Nesse sentido, governos, autoridades de saúde pública e empresas digitais devem buscar meios para combater o impacto que as informações falsas estão causando, com vistas a perdurar até mesmo quando a pandemia da COVID-19 terminar (Ali \& Kurasawa, 2020).

Nesse sentido, algumas ações tomadas por agências governamentais em parceria com o Facebook, Twitter e Instagram estão colaborando para sinalizar, verificar fatos e até mesmo remover informações falsas ou desatualizadas, de forma a impedir que os esforços da saúde pública sejam ineficientes (Limaye et al., 2020).

A OMS (2020) adicionou em sua plataforma uma seção denominada "caça ao mito" sobre informações da Covid-19, com vistas a refutar uma variedade de notícias falsas sobre a doença. Da mesma forma, o Ministério da Saúde do Brasil (2020), disponibilizou um número de WhatsApp para envio de mensagens à população brasileira, com o objetivo de responder sobre a veracidade das informações virais. O WhatsApp e Poynter's International Fact-Checking Network (IFCN [Rede Internacional de Verificação de Fatos]) também criaram um serviço de esclarecimento para sanar dúvidas e combater notícias falsas envolvendo a pandemia (Poynter, 2020a).

Nesta perspectiva, as temáticas de fake news e pós-verdade, tornaram-se bastante populares nas mídias sociais e nos meios acadêmicos, com inúmeras publicações nos últimos anos (Angermuller, 2018; Chambers, 2020; Iosifidis \& Andrews, 2020; Maus, 2020). No entanto, há incipientes estudos sobre notícias falsas e pós-verdade durante a pandemia da Covid-19, especificamente por se tratar de um assunto emergente, por isso, a credibilidade é o elemento que certifica uma informação como verdadeira, e, portanto, confiável.

Diante do exposto, o objetivo deste estudo buscou verificar elementos que possibilitam aferir credibilidade às informações disponíveis na Web. Por sua natureza, esse estudo de reflexão é exploratório, descritivo, pois aplicou-se a revisão de literatura para a explanação e ponderação sobre os temas tratados neste escopo. A revisão de literatura focou nos temas sobre fake news, pós-verdade, infodemia, desinformação, checagem e credibilidade de informação. A justificativa para a realização deste estudo se deu pela relevância da temática neste atual momento de pandemia, considerando-se ainda a existência do grande número de informações inverídicas divulgadas pela mídia e, em grupos de conversas informais, o que pode prejudicar na compreensão da gravidade da doença e, no entendimento de como lidar com as questões de combate da COVID-19.

\section{Fake news, pós-verdade, infodemia e desinformação}

$\mathrm{O}$ ato de mentir e inventar histórias é algo que vem de antes de cristo, Darnton (2017) em seu livro sobre a história da fake news, relata a origem histórica e antiga desse tipo de informação. O imperador romano Augusto IV a.c. usa do recurso da mentira para difamar rivais. A famosa obra Anecdota, do historiador Procópio, conhecido pelo uso de informações duvidosas, das quais tinham o intuito de manchar a imagem do imperador Justiniano. Pietro Aretino escreveu profanidades sobre o concorrente ao pontifício, a fim de manipular as eleições de 1522, o ato ficou conhecido como pasquinada, devido ao local (estátua de Pasquino) no qual ele dependurava as suas alegações. No século XVII uma espécie de jornal, chamado de Canard, o qual vendia informações falsas nas ruas de Paris. O Canard Enchainé, criado em 1915 sobrevive com a venda de "conteúdos satíricos" até os dias de hoje. Outro material famoso por publicar informações duvidosas era o Le Gazetier cuirassé, de 1771. O The Morning Post, criado em 1772 pelo reverendo Henry Bate, no qual publicava, em sua maioria, fofocas e informações falsas, 
em um tipo de escrita chamada de "parágrafo". Em 1788, Londres tinha oito jornais quinzenais e nove jornais semanais, todos continham publicações de "parágrafos", com enfoque em fofocas e informações falsas.

No entanto, o fenômeno das fake news e pós-verdade ganharam visibilidade no final de 2016, quando passaram a ser objeto de estudo nos últimos anos, devido a dois fatores que chamaram a atenção da opinião pública. O primeiro foi o Bretix, abreviação das palavras inglesas britain (Bretanha) e exit (saída), que se popularizou com as campanhas pró e contra a saída do Reino Unido da União Europeia (Genesini, 2018), marcadas pela disseminação de mentiras e informações inverídicas nas mídias sociais por candidatos ou figuras-chave de campanha eleitoral do Reino Unido (Cardoso et al., 2018). O segundo foi à disputa eleitoral entre Donald Trump e Hillary Clinton para a presidência dos Estados Unidos da América (EUA) que ocorreu em 2016. Ambos os candidatos detinham de apoio de diversos sites e das redes sociais, passaram a alimentar notícias falsas com o objetivo de aludir que o adversário não era adequado ao cargo; ao final das eleições o candidato Donald Trump venceu e o termo fake news ganhou mais popularidade (Paula, Silva \& Blanco, 2018).

Posteriormente, o termo "pós-verdade" foi definido pelo English Oxford Living Dictionaries (2016) como sendo "relativo às circunstâncias nas quais fatos objetivos têm menor influência em moldar a opinião pública do que apelos à emoção e crenças pessoais". Nesse sentido, pós-verdade é considerada como uma fake new que, se divulgada, pode ser aceita como verdadeira ou falsa, não pela sua veracidade e confiabilidade, mas, por estar de acordo com as crenças e valores de cada indivíduo (Seixas, 2019).

A pós-verdade ficou ainda mais em evidência devido à matéria Art of Lie, capa da revista britânica The Economist, que responsabiliza a internet e as redes sociais pela sua disseminação (Spinelli \& Santos, 2018). Acrescido a isso, com o surgimento da internet e das tecnologias da informação e comunicação (TIC), criou-se um cenário ideal para a propagação destes fenômenos, pois é possível ter livre expressão para produzir e emitir qualquer tipo de informação (Cardoso et al., 2018).
Isso se tornou ainda mais evidente durante a pandemia da Covid-19, pois o avanço tecnológico vinculado às redes sociais faz com que notícias falsas sejam criadas e compartilhadas rapidamente entre a população, causando uma desinformação prejudicial, ao subestimar os riscos da doença, e, ao promover ações contrárias àquelas orientadas pelos profissionais da saúde, no mundo todo (Neto et al., 2020).

Um estudo realizado pela Escola Nacional de Saúde Pública [ENSP/FIOCRUZ] (Fundação Oswaldo Cruz -Fiocruz, 2020) mostrou que no Brasil, as redes sociais: Instagram, Facebook e Whatsapp são as principais plataformas utilizadas para a disseminação de notícias falsas sobre a Covid-19. Os dados apontaram que $10,5 \%$ das notícias falsas foram postadas no Instagram, 15,8 \% no Facebook e 7,7 \% no Whatsapp, sendo que 26,6 \% das fake news publicadas no Facebook são sobre proteção contra a doença.

O alto volume de informações controversas sobre um determinado assunto ficou conhecida como Infodemia, ou, uma epidemia de informações falsas. A Organização Pan-Americana de Saúde (OPAS), lançou um informativo sobre a infodemia e a desinformação na luta contra a Covid-19, no qual a palavra infodemia é classificada como: "um excesso de informações, algumas precisas e outras não, que tornam difícil encontrar fontes idôneas e orientações confiáveis quando se precisa" outra palavra que aparece neste informativo é a desinformação, classificada como, "uma informação falsa ou imprecisa cuja intenção deliberada é enganar" (OPAS, 2020, p. 2).

A infodemia é uma prática considerada pela OPAS como algo altamente prejudicial para as pessoas, já que afeta a vida, saúde e até a sanidade mental dos indivíduos, que no caso da Covid-19, cresceu cerca de $50 \%$ a $70 \%$, devido a facilidade de publicação de conteúdos na internet. "É fundamental interromper este ciclo perigoso: a desinformação se expande no mesmo ritmo que a produção de conteúdo, e as vias de distribuição se multiplicam. Assim, a própria infodemia acelera e perpetua a desinformação" (OPAS, 2020, p. 3).

Segundo Pimenta e Belda (2018a), autores do manual de credibilidade informacional, o ecossistema da desinformação funciona com base em três pilares: na 
falsa conexão, falso contexto e na manipulação do conteúdo, dois quais geram quatro possíveis "produtos", o infográfico (Infográfico 1) abaixo exemplifica as situações.

O infográfico revela que há possibilidades tipológicas divergentes que envolvem o ecossistema da desinformação, fazendo surgir possíveis infortúnios envoltos da informação, como elencado acima: sátira, conteúdo enganoso, conteúdo impostor e conteúdo fabricado, se originam com base na informação publicada, das quais têm objetivos e origens distintas.
Esse é o cenário da sociedade do século XXI, marcado pelo movimento da pós-verdade, no qual o indivíduo acredita no que lhe convêm, devido ao número crescente de fake news (informações falsas) em um contexto de infodemia (enxurrada de informações controversas), juntamente com a desinformação (conteúdo com intuito enganoso), nada mais é que um contexto no qual a informação sem validade científica, comprobatória e de credibilidade acabam sendo absorvidas por inúmeros usuários das redes sociais e internet, prejudicando muitas pessoas.
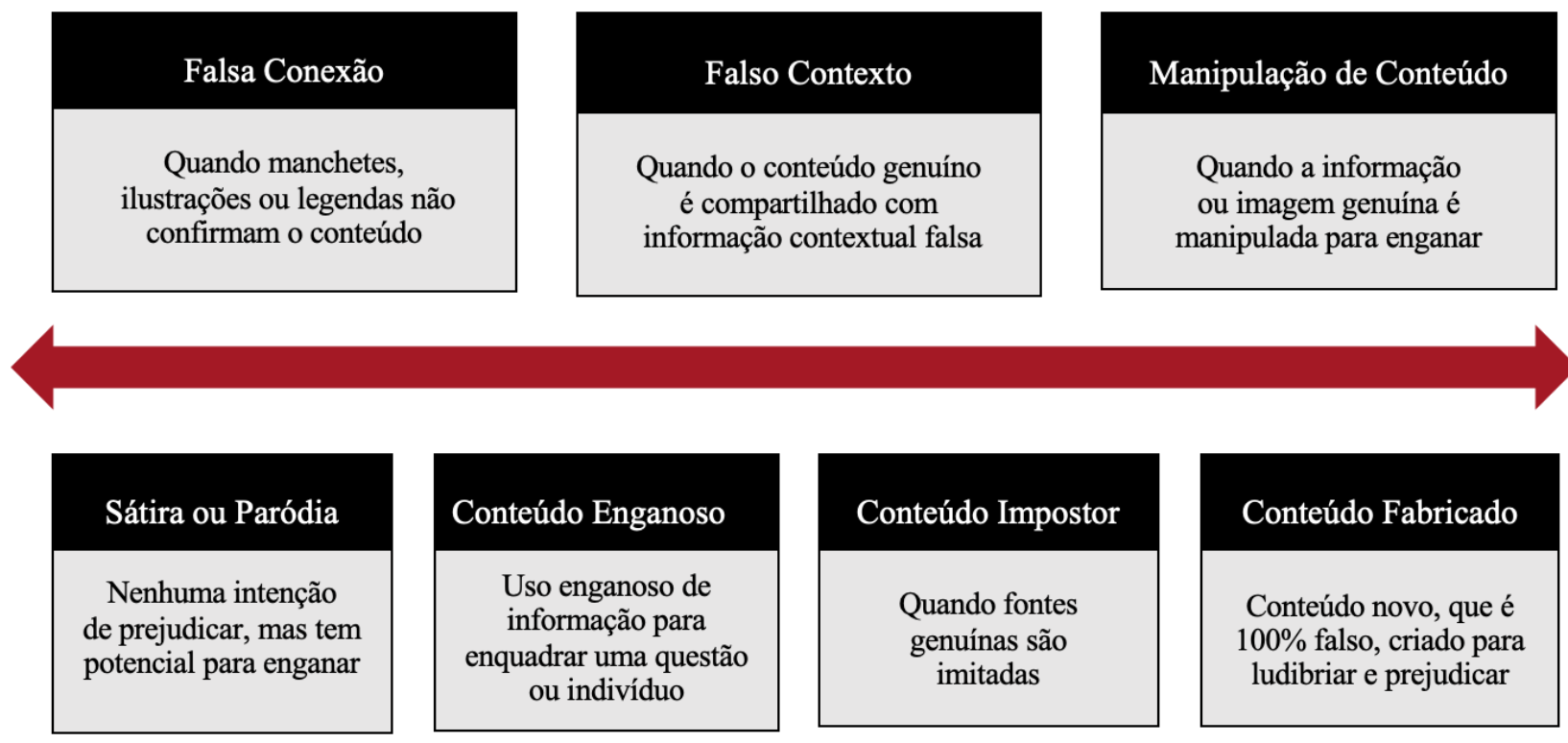

Infográfico 1. Representação do ecossistema da desinformação.

Fonte: autoria de Claire Wardle, obtido no manual de Pimenta e Belda (2018a).

Com vistas a minimizar os impactos da disseminação de informações falsas e a desinformação, várias plataformas de checagem de conteúdo foram criadas mundo afora, a fim de contribuir no combate desse cenário informacional tão prejudicial quanto o atual vírus. No Brasil as plataformas Aosfatos (2020a), a Agência Lupa (2020) e Estadão Verifica (2020) são as principais responsáveis pela checagem de conteúdo da web. Shimizu (2020) acredita que a mídia convencional e os jornalistas têm um papel crucial no fornecimento de informações precisas ao público, ajudando a combater as fake news e a desinformação.

\section{2.l Checagem de informação}

A checagem de informação é um procedimento que requer um método ou ferramentas, em um processo bem definido e transparente, que possibilite a checagem e rechecagem de qualquer informação que esteja disponível na web.

No contexto digital, um dos recursos de checagem de informação pode ser feita por meio de sistemas preparados para esse fim, Mesquita, et al. (2020), sugerem o uso de mecanismos de checagem por meio de recursos computacionais, no uso de Inteligência Artificial, jun- 
tamente como o processamento da Linguagem Natural, e o Aprendizado de Máquina, ambos recursos podem ajudar a identificar esse grupo de informações inverídicas em grande quantidade (Mesquita et al., 2020). Em analogia, a sugestão dos autores se associa ao trabalho que os softwares de plágio já realizam, contudo, a nível de metabuscadores nos diversos sistemas integrados ao Google e outras ferramentas de busca, em uma aplicação que ainda não está direcionada para a certificação de conteúdos dispostos na web.

O fact-checking é um método jornalístico que vem sendo amplamente aplicado no combate das fake news e desinformação, por meio de um trabalho minucioso de checar e creditar fontes e publicações sobre assuntos de interesse público. "A checagem de fatos é um método jornalístico por meio do qual é possível certificar se a informação apurada foi obtida por meio de fontes confiáveis" (Aosfatos, 2020a).

O termo fact-checking (checagem de fatos), de aplicação da prática de checagem de informações é oriundo da década de 90. Em 2003 se difundiu como um método científico jornalístico, surgindo para padronizar a prática aplicada na conferência da veracidade das informações disponíveis em uma publicação, por meio de uma conduta ética e transparente.

Toda profissão reconhecida tem um código de ética e de conduta para regulamentar a sua atuação, o Instituto Poynter (2016), fundado em 1975 é um dos órgãos que promove o ensino e aprendizado para a atuação jornalística nas mídias, principalmente sobre a ética e boa conduta, capacita e forma pessoas para trabalharem com a verificação e checagem de fatos e habilidades digitais a fim de combater a desinformação e a mentira.

O método de checagem de informação visa a transparência na verificação da credibilidade de cada fonte, as quais devem ser publicadas junto a informação que foi checada. Cada plataforma define a sua política de checagem, transparência e creditação das publicações analisadas pelos profissionais responsáveis pela conferência das fontes.

O método de checagem segue às etapas de verificação das fontes utilizadas na produção do conteúdo, tudo é verificado e analisado, definindo o grau de credibili- dade e veracidade que a publicação tem. A checagem é feita em textos, imagens, áudios e vídeos, por meio de sistemas, plataformas e pessoas qualificadas e comprometidas com a realização do método.

Como cada plataforma tem seu método, apresentamos as etapas do método da plataforma Aosfatos (2020b), a qual utiliza em seu processo de checagem sete passos:

1) Selecionamos uma informação pública a partir de sua relevância — seja porque uma autoridade pública a endossou, seja porque tem alto engajamento nas redes sociais.

2) Consultamos quem divulgou a informação primeiro para checar sua veracidade.

3) Uma vez confirmada a origem da desinformação, procuramos por fontes de origem confiável para conferir se a mensagem confere.

4) Se há necessidade, consultamos fontes oficiais, para confirmar ou refutar a informação.

5) Se ainda não for suficiente, consultamos fontes alternativas, que podem subsidiar ou contrariar dados oficiais. Registramos, de modo acessível, no texto.

6) Contextualizamos.

7) Classificamos a declaração com uma das sete categorias: verdadeiro, impreciso, exagerado, contraditório, insustentável, distorcido ou falso (Aosfatos, 2020b).

Na mesma corrente, a plataforma Invid (2020), apresenta alguns de seus recursos de uso aplicados para a checagem de conteúdo, como: plugins de verificação, aplicativos de verificação, painel de análises, serviço móvel, serviço online de fragmentação e pesquisa reversa de imagem. Tanto os recursos pessoais quanto os tecnológicos são essenciais na aplicação da checagem de informação, pois potencializam e maximizam a cobertura de atuação de profissionais capacitados neste cenário de fakes e mentiras, na web.

A IFCN é um exemplo desse trabalho primoroso de checagem e verificação de conteúdo, foi criada em ja- 
neiro de 2020 para combater a infodemia. O serviço passou a ser de utilidade pública e mundial, na América Latina a rede conta com 34 organizações de 17 países ibero-americanos; no Brasil as agências, Aos Fatos e Estadão Verifica, são as responsáveis por checar as postagens sobre a COVID-19 (Latamchequea, 2020). Essa rede de crowdsourcing (colaboração coletiva) é liderada pelo Instituto Poynter (2020b), do qual, conta com a parceria de várias agências locais de inúmeros países, para checar e atualizar os dados diariamente, por meio desse trabalho, ao todo, já foram feitas mais de 6600 verificações relacionadas à 70 países, em mais de 40 idiomas.

Toda essa 'força tarefa' de checagem e conferência de fatos, publicações e dados são para combater as fakes na web, creditando todos os conteúdos que foram conferidos, o que torna possível identificar o que é falso do verdadeiro, ou do que é credível do não credível!

\subsection{Credibilidade da informação}

A credibilidade é uma característica vinculada à pessoa, ao caráter, se originou primeiramente na oralidade da retórica, ato de falar, discursar, convencer, e se difundiu no registro da escrita. A ética tem uma forte relação com a credibilidade e a confiança aferida, seja pela oralidade ou escrita (Serra, 2006a). A comunicação é simbólica, mas ainda hoje a credibilidade informacional está relacionada com o que se diz e quem o diz, essa comunicação se difunde por meio da experiência, do ato e na confiança de seu caráter! Desta forma, a premissa, base da credibilidade, consiste no ato de convencer um indivíduo a acreditar em algo, por meio de sua fiabilidade.

A credibilidade de uma informação é parte de um processo de comunicação, enreda uma relação de confiança, está interligada ao caráter imparcial da informação, do autor e da fonte. O processo informacional requer competência e seriedade para assim apresentar a verdade dos fatos (Serra, 2006b, 2006c). O processo de identificação e verificação das fontes, são feitas antes de atribuir-lhes a credibilidade (Traquina, 2004).

Os estudos sobre credibilidade da informação iniciaram por volta de 1950, por pesquisadores da área da Psicologia; nesse campo a perspectiva dos estudos tinham o objetivo de investigar a credibilidade como "uma construção subjetiva", entre indivíduos que obtém a informação, essa subjetividade está relacionada com a credibilidade da fonte, da mensagem e da credulidade da audiência (Terra \& Sá, 2012). Já, a Ciência da Informação-CI passou a estudar o cenário ao entorno da credibilidade em meados de 1990, seu foco estava direcionado para as fontes em meios digitais, possuindo um perfil informacional diferente das fontes em formato físico, por isso, o entendimento da credibilidade informacional da CI foi de que, ela é "uma propriedade objetiva da informação, associada à ideia de "qualidade" dessa informação em termos de relevância, correção ou utilidade relativamente a um fim específico" (Terra \& Sá, 2012, p. 2).

A credibilidade informacional está ligada ao universo no qual ela permeia (produtor/responsável, canais e fontes informacionais); os elementos que à constitui colaboram na aferição ou não de credibilidade da informação, seja ela digital ou física.

Nesse sentido, Rockembach (2012) explicita que, as Bibliotecas, Arquivos ou repositórios de organizações, tendem a ter uma alta credibilidade, pois mantém acervos, mesmo que digitais, de fontes confiáveis, já analisadas por profissionais e organismos científicos ou sociais.

Pimenta e Belda (2018b), sinalizam doze elementos que norteiam a credibilidade de um canal de comunicação, no qual a informação é disponibilizada:

a) Apresenta o código de ética.

b) Deixa claro quais são suas diretrizes de financiamento.

c) Expõe a sua missão e valores.

d) Prática a admissão de erros e correções.

e) Aplica práticas que visam a precisão e, de padrões de verificação.

f) Fornece a identificação dos responsáveis pelas informações.

g) Organiza o conteúdo por meio da categorização de cada tipo de informação. 
h) Apresenta a indicação de fontes.

i) Expõe o método empregado na realização do conteúdo.

j) Sinaliza a origem de cada publicação, se é local, regional ou mundial.

k) Apresentar perspectivas de diferentes vertentes.

1) Permite receber feedback.

A aferição de credibilidade da informação envolve o olhar sobre todo o cenário de constituição, de formação, de disseminação e de responsabilidade do conteúdo analisado, o qual tem um objetivo, um propósito à tratar, que pode ser sobre pessoas, assuntos, objetos, ações e práticas, em contextos sociais distintos; olhar para todos esses elementos ajuda a entender a finalidade de uma publicação e a que ela se destina.

Existem outros elementos que ajudam na aferição de credibilidade à uma informação em meio eletrônico, das quais estão diretamente relacionadas com as características do ambiente e da informação que foi publicada; conforme as indagações apresentadas por Fachin e Blattmann (2016), e por Campello e Caldeira (2008):

a) Há informações sobre responsáveis pelo canal ou sobre a instituição.

b) O canal de comunicação disponibiliza a data da publicação e da atualização das informações e conteúdos.

c) O canal é um veículo de comunicação de prestígio.

d) Com que frequência esse canal público esse tipo de informação.

e) O endereço eletrônico, a url da página, é de domínio: .com; .edu; .org; .gov, etc.

f) Indica a forma de acesso ao conteúdo, se é pago ou gratuito.

g) Apresenta um campo de busca.

h) A página sinaliza as fontes de informação e dados apresentados no conteúdo.

i) O canal oferece uma lista de referência para a consulta e conferência das informações utilizadas na construção do texto e conteúdo. j) Apresenta a autoria ou responsável pelo conteúdo disposto.

k) Disponibiliza uma pequena biografia do autor ou responsável pela publicação.

1) O responsável pela informação é alguém com formação ou atua na área de conhecimento do qual pública.

Essas perguntas também auxiliam no entendimento da relação que a informação tem com o canal e com a pessoa responsável, pois, um ambiente informacional que pretende ser reconhecido como fidedigno deve expor o máximo possível de informações sobre o canal, equipe, responsabilidade, publicações e o grau de comprometimento com o público leitor de seu conteúdo; dando subsídios ao mais elevado nível, para que o indivíduo possa conferir se o canal e as informações têm certa confiabilidade ao publicar certas informações.

González de Gomez (2007), acreditam que os indicadores de credibilidade da informação estão relacionados com "o comportamento passado; a reputação; a oportunidade (ou a possível existência de 'bias'); o contexto; traços culturais e identidade; sua apresentação; os cuidados; referências e contexto em que se disponibiliza uma fonte", tudo é relevante e pertinente para a aferição da credibilidade de uma fonte ou informação.

A credibilidade de uma fonte pode direcionar para o uso ou não de determinados canais de comunicação na medida em que se relaciona a integridade desse conteúdo, ela está vinculada diretamente com a "confiabilidade, justiça, integridade, utilidade e precisão" (Kyungeun \& Baek, 2019, p. 993, tradução nossa), das informações contidas em certos canais.

Nesse sentido, ressalta-se que, em tempos da COVID-19e diante de tantas notícias replicadas na internet, sejam elas de ordem governamental, midiáticos ou pelas redes sociais, se faz necessário expor, validar e comprovar as fontes de informação para que as pessoas não reproduzam fake news. As plataformas de validação se juntam nesta luta, verificando diversas publicações a fim de identificar e sinalizar canais que apresentam comportamentos que exprime a desinformação e a infodemia, dos quais prestam um desserviço à toda uma sociedade. 


\section{Conclusões}

Considerando que o universo informacional é paralelamente multifacetado e que cada área de conhecimento o tem de forma distinta, as leituras e autores utilizados neste estudo apresentam elementos que ajudam a entender como a informação se tornou algo controverso; por meio do cenário do qual a sociedade atual se encontra inserida, no movimento da pós-verdade e da infodemia. A existência desses movimentos em pleno século XXI comprovam o quanto a informação está suscetível de ser aplicada em detrimento de alguns ou causa, permeando o universo da desinformação por motivações particulares, a fim de manipular e confundir pessoas, se beneficiando dos recursos da web para disseminar esse tipo de conteúdo.

O fato de existirem informações e canais de divulgação de conteúdos pouco credíveis não é novidade deste milénio, como já foi visto, a mentira e a manipulação de informações é algo do qual sempre esteve presente na sociedade, a novidade está justamente na forma e rapidez com que esse tipo de conteúdo se propaga na web, pois utiliza dos meios de comunicação de massa para atingir o maior número possível de indivíduos.

Com a quantidade de informação que circula livremente pela web, é quase que impossível classificar tudo o que é do que não é confiável. Esse cenário se agravou com o surgimento das fakes news, tornando necessária e extremamente relevante a existência de mecanismos de checagem e creditação de conteúdo da web.

Neste estudo conseguimos levantar duas maneiras de realizar a checagem de conteúdos: a primeira consiste no uso de mecanismos computacionais de busca e identificação, que possam certificar conteúdos, por meio de aplicativos e softwares específicos, tem também os similares ao sistema de busca e rastreio feitos por metabuscadores. A segunda forma identificada é fact-checking, uma prática exercida por pessoas, quase sempre atribuída por equipes jornalísticas, aplicada com base em métodos reconhecidos pela comunidade científica, viabilizando a creditação dessas informações, mas que tem limitações quanto ao grande número de informações disponíveis na web e o tempo que esse processo de checagem individual leva, mas que é o método mais confiável e aplicado até o momento.
Neste cenário, vale destacar também a importância dos profissionais da informação, mais especificamente os que atuam na área da Ciência da Informação. Neste momento de pandemia da COVID-19 muitas unidades de informações se encontram fechadas, devido à necessidade do isolamento social, mas, o trabalho desses profissionais em realizar levantamento, compilação e apresentação de conteúdos fidedignos na web, colabora no combate à desinformação e a propagação de fake news, uma vez que passam a fornecer fontes confiáveis aos usuários. Outra frente que esses profissionais vêm atuando é no auxílio e interlocução com a comunidade científica, ajudando aos pesquisadores na identificação de conteúdos para a elaboração e publicação de pesquisas para o combate da doença.

Desta forma, tendo em vista que as chamadas fakes news estão dominando o cenário mundial, há a possibilidades da criação de ferramentas integradas para a avaliação das informações contidas nesses ambientes, a fim de esclarecer o que são e como são as notícias falsas, diferenciando-as daquelas confiáveis. Por fim, no que tange ao ambiente tecnológico, essas fontes podem ser avaliadas sob a ótica da cientificidade, porém, ainda passíveis de contestação.

\section{Referências}

1. Agência Lupa. (2020). Sobre. https://piaui.folha.uol. com.br/lupal

2. Ali, Harris; Kurasawa, Fuyuki (2020). COVID19: Social media both a blessing and a curse during coronavirus pandemic. The Conversation. https://theconversation.com/ covid19-social-media-both-a-blessing-and-a-curse-during-coronavirus-pandemic-133596

3. Aosfatos (2020a). O que é checagem de fatos - ou fact-checking? Aosfatos. https://www.aosfatos.org/checagem-de-fatos-ou-fact-checking/

4. Aosfatos (2020b). Nosso Método. Aosfatos. https:// www.aosfatos.org/nosso-m\%C3\%A9todo/

5. Angermuller, Johanens (2018). Truth after post-truth: For a strong programme in discourse studies. Palgrave Communications, 4(30). https://doi.org/10.1057/ s41599-018-0080-1 
6. Avaaz (2020). O Brasil está sofrendo uma infodemia de Covid-19: Os brasileiros acreditam mais em notícias falsas que os italianos e os estadunidenses. https://secure. avaaz.org/campaign/po/brasil_infodemia_coronavirus/

7. Brasil (2020). Saúde sem Fake News. Ministério da Saúde. https:/www.saude.gov.br/fakenews

8. Campello, Bernadete Santos; Caldeira, Paulo da Terra (2008). Introdução às fontes de informação. Belo Horizonte: Autêntica Editora.

9. Cardoso, Gustavo; Baldi, Vania; Pais, Pedro; Paisana, Miguel;Quintanilha,Tiago;Couraceiro,Paulo(2018).AsFake News numa sociedade pós-verdade Contextualização, potenciais soluções e análise. Relatório Obercom. https:// obercom.pt/wp-content/uploads/2018/06/2018-Relatorios-Obercom-Fake-News.pdf

10. Chambers, Sinomw (2020). Truth, Deliberative Democracy, and the Virtues of Accuracy: Is Fake News Destroying the Public Sphere? Political Studies. https://doi.org/10.1177/0032321719890811

11. Darnton, Robert. (2017). The true history of fake news. The New Yourk Review of Books. https://www.nybooks.com/ daily/2017/02/13/the-true-history-of-fake-news/

12. English Oxford Living Dictionaries (2016). Pós-verdade. Word of the Year 2016. https://goo.gl/jYmblQ

13. Estadão Verifica (2020). Sobre. https://politica.estadao. com.br/blogs/estadao-verifica/

14. Fundação Oswaldo Cruz-Fiocruz (2020). Pesquisa revela dados sobre 'fake news' relacionadas à Covid-1. FIOCRUZ/Escola Nacional de Saúde Pública. https://portal.fiocruz.br/noticia/pesquisa-revela-dados-sobre-fake-news-relacionadas-covid-19

15. Fachin, Juliana; Blattmann, Ursula. (2016). Avaliação de fonte de informação. Em Ursula Blattmann; William Vianna (Orgs.), Inovação em Escolas com Bibliotecas (pp. 197-206). Florianópolis: Dois Por Quatro.

16. Genesini, Silvio (2018). A Pós-verdade é uma notícia falsa. Revista USP, (116), 45-58. https://doi.org/10.11606/ issn.2316-9036.v0ill6p45-58

17. González de Gomez, Maria Nélida (2007). Novas configurações do conhecimento e validade da informação. Anais do Encontro Nacional de Pesquisa em Ciência da Informação. Salvador: Universidade Federal da Bahia. http://repositorios.questoesemrede.uff.br/repositorios/ bitstream/handle/123456789/24/GTl--177.pdf?sequence $=1$

18. ICFJ (2020). UN-ICFJ Research Examines COVID-19 Disinformation. https://www.icfj.org/news/un-icfj-research-examines-covid-19-disinformation

19. Invid (2020). Tecnologias InVID. https://www.invid-project.eu/other-invid-technologies/

20. Iosifidis, Petros; Andrews, Leighton (2020). Regulating the internet intermediaries in a post-truth world: Beyond media policy? International Communication Gazette, 82(3), 211-230. https://doi.org/10.1177/1748048519828595

21. Junior, G. C. (2019). Pós-verdade: a nova guerra contra os fatos em tempos de fake News. Educação Temática Digital, 2l(1), 278-284. https://doi.org/10.20396/etd. v2lil.8652833

22. Kyungeun, Jang; Baek, Min (2019). When information from Public Health Officials is untrustworthy: The use of online news, interpersonal networks, and social media during the MERS outbreak in South Korea. Journal Health Communication, 34(9), 991-998. https://doi.org/10.1 080/10410236.2018.1449552

23. Latamchequea (2020). Informação verificada sobre o coronavírus. http://www.coronaverificado.news/

24. Limaye, Rupali; Sauer, Molly; Ali, Joseph; Bernstein, Justin; Wahl, Brian; Barnhill, Anne.; Labrique, Alain (2020). Building trust while influencing online COVID-19 content in the social media world. The Lancet Digital Health. https://doi.org/10.1016/S2589-7500(20)30084-4

25. Maus, Katharine Eisaman. (2020). Fake News. New Literary History, 5l(1), 249-252. https://doi.org/10.1353/ nlh.2020.0014 h

26. Mesquita, Claudio; Oliveira, Anderson; Seixas, Flávio. Paes, Aline (2020). Infodemia, fake news and medicine: Science and the quest for truth. International Journal of Cardiovascular Sciences, 33(3), 203-205. http://dx.doi. org/10.36660/ijcs.20200073

27. Neto, Mercedes; de Oliveira, Tatiana; Porto, Fernando; Rafael, Ricardo; Fonseca, Mary; Nascimento, Julia (2020). Fake news no cenário da pandemia de Covid-19. Cogitare Enfermagem, 25. http://dx.doi.org/10.5380/ce. v25i0.72627 
28. OPAS (2020). Entenda a infodemia e a desinformação na luta contra a covid-19. OPAS: Departamento de Evidência e Inteligência para Ação em Saúde. https://iris.paho. org/bitstream/handle/10665.2/52054/Factsheet-Infodemic_por.pdf?sequence=3

29. Paula, L. T.; Silva, T. R. S.; Blanco, Y. A. (2018). Pós-verdade e Fontes de Informação: um estudo sobre fake News. Revista Conhecimento em Ação, 3(1). https://revistas. ufrj.br/index.php/rca/article/view/16764

30. Pimenta, Angela; Belda, Francisco (2018a). A desordem da informação. São Paulo: PROJOR-Instituto para o desenvolvimento do Jornalismo. https://www.manualdacredibilidade.com.br/desinformacao

31. Pimenta, Angela; Belda, Francisco (2018b). Sistema de indicadores de credibilidade. São Paulo: PROJOR-Instituto para o desenvolvimento do Jornalismo. https:// www.manualdacredibilidade.com.br/indicadores

32. Poynter (2016). International Fact-Checking Network's code of principles. https://www.poynter.org/ fact-checking/2016/fact-checkers-around-the-worldagree-on-shared-code-of-principles/

33. Poynter (2020a). New WhatsApp chatbot unleashes power of worldwide fact-checking organizations to fight COVID-19 misinformation on the platform. Poynter's International Fact-Checking Network. https:/www.poynter.org/fact-checking/2020/ poynters-international-fact-checking-network-launches-whatsapp-chatbot-to-fight-covid-19-misinformation-leveraging-database-of-more-than-4000-hoaxes/

34. Poynter (2020b). Fighting the Infodemic: The $\# \mathrm{Co}-$ ronaVirusFacts Alliance. https://www.poynter.org/ coronavirusfactsalliance/

35. Rockembach, Moisés (2012). Modelo de evidência da informação em plataformas digitais: estudo exploratório no âmbito da ciência da informação (tese de doutorado em Ciência da Informação). Universidade do Porto, Portugal. https://doi.org/10.18377/2316-7300/informacaoarquivistica. v2nlp89-109

36. Seixas, Rodrigo (2019). A retórica da pós-verdade: o problema das convicções. Revista Eletrônica de Estudos Integrados em Discurso e Argumentação, 18. https://doi.org/10.17648/eidea-18-2197
37. Shimizu, Kazuki (2020). 2019-nCoV, fake news, and racism. The Lancet, 395(10225), 685-686. https://doi. org/10.1016/S0140-6736(20)30357-3

38. Serra, Paulo (2006a). Web e credibilidade - O caso dos blogs. Biblioteca on-line de Ciências da Comunicação, Universidade Fernando Pessoa. http://www.bocc.ubi. pt/_esp/autor.php?codautor=37

39. Serra, Paulo (2006b). A credibilidade da informação na web. Biblioteca on-line de Ciências da Comunicação. Universidade Fernando Pessoa. http://www.bocc.ubi.pt/pag/serra-paulo-credibilidade-web.pdf

40. Serra, Paulo (2006c). O princípio da credibilidade na selecção da informação mediática. Biblioteca on-line de Ciências da Comunicação. Universidade Fernando Pessoa. http://www.bocc.ubi.pt/pag/serra-paulo-credibilidade-seleccao-informacao.pdf

41. Silva, Renato; Santos, Roney; Almeida, Tiago; Pardo, Tiago (2020). Towards automatically filtering fake news in Portuguese. Expert Systems with Application, 146(15), e-p. 13199. https://doi.org/10.1016/j.eswa.2020.113199

42. Sinatra, Gale; Lombardi, Doug (2020). Evaluating sources of scientific evidence and claims in the post-truth era may require reappraising plausibility judgments. Educational Psychologist, 55(3) 1-12. https://doi.org/10.1080/0046 1520.2020 .1730181

43. Spinelli, Egle; Santos, Jessica (2018). Jornalismo na era da Pós-Verdade: fact-checking como ferramenta de combate às fake news. Revista Observatório, 4(3), 759-782. https://doi.org/10.20873/uft.2447-4266.2018v4n3p759

44. Terra, Ana Lúcia; Sá, Salvina (2012). Tudo o que vem à rede é peixe? A credibilidade da informação na web. ACTAS: Congresso Nacional de Bibliotecários, arquivistas e documentalistas, Lisboa, PT. https://bad.pt/publicacoes/ index.php/congressosbad/article/view/441/pdf

45. Traquina, Nelson (2004). Teorias do Jornalismo: porque as notícias são como são. Florianópolis: Insular.

46. Unesco News (2020). During this coronavirus pandemic, 'fake news' is putting lives at risk: Unesco. https:// news.un.org/en/story/2020/04/1061592

47. OMS (2020). Coronavirus disease (COVID-19) Pandemic. https://www.who.int/emergencies/diseases/ novel-coronavirus-2019/advice-for-public/myth-busters 